was very firmly adherent, and was with difficulty dissected from the organ. Beneath this adherent piece of the membrane there was found a ruptured Graafi $₫$ n follicle, with recent corpus luteum. In the cavity of the uterus a thick membrane of villous character adhered to the posterior wall of the fundus.

It seemed therefore that the inflammation was at first set up during menstruation, around the ruptured follicle, producing pelveo-peritonitis, and that this had become enclosed in a false membrane as the first stage towards cure, and that the sac enclosing the limited effusion had been burst by some mechanical cause, and so had set up the fatal general peritonitis.

\section{ST. BARTHOLOMEW'S HOSPITAL, CHATHAM.}

CASES OF DISLOCATION OF 'IHE PATELLA ; REMARKS.

(Under the care of Mr. NANkIVELL.)

CASE 1. Dislocation of right patella upwards. -T. Ca labourer, aged twenty-eight years, was admitted on January 31st, 1877. He stated that on or about December 1st, 1876, when returning from work, he slipped off the kerbstone and fell on his right knee. Being unable to walk he was carried home, where he remained for about three weeks without any medical attendance. During the latter part of this time he managed to crawl about the room by the aid of the table and chairs. He then presented himself at an infirmary, where he was treated for a month as an outpatient. On admission into this hospital the right kneejoint was found to be somewhat swollen and the entire patella was drawn upwards, its lower border being two inches from the upper end of the tibia. Between these two points the fingers sank easily into the joint. The ligamentum pateliæe was ruptured at its attachment to the patella. The patient could slowly flex his knee, but could not extend it. He got about by the aid of a stick. He left the hospital on February 6th, 1877.

CASE 2. Dislocation and redislocation of the right patella upwards.-Mr. F-, aged forty, a shoemaker, fell downstairs on Feb. 26th, 1880. On admission the entire right patella was found to be dislocated upwards, with no portion of the ruptured ligament attached to it. A Melntyre's splint was applied, and the leg elevated, the patient himself being placed in a semi-recumbent position. On March lst a pad of lint was placed above the patella, and it was drawn down by a figure-of- 8 bandage. The McIntyre splint was reapplied. At the end of the month the patella was in situ, and appeared to be firmly united to its ligament, the poin of rupture being marked by considerable thickening. The limb was put up in plaster-of-Paris. On April isth the plaster having cracked it was removed, and a back splint substituted. He was made an out-patient. On May 3id he could get about without a splint, and could walk a mile and three-quarters in half an hour. The patella was in its normal position, and was firmly united to the ligament. He had full power of flexion and extension. On May 5th, whilst walking along a dark passage, he missed his footing, and injured his knee again. On admission he was found to have redislocated the patella, but the bone was not drawn up quite so much as on the first occasion. The same treatment was adopted, and persevered in till July 8th, when, on removal of the plaster-of-Paris bandage, the patella was found to be in its proper position, and firmly united to its ligament. He was directed to wear a knee-cap.

CASE 3. Vertical dislocation of the left patella.-On October 31st, 1881, H. W-, a navvy, aged twenty-three years, was pulling a plank with a plank-hook, when he stumbled against a heap of earth lying behind him and fell backwards. Being unable to walk, he was carried to the hospital. On admission, the patella was found with its inner edge fixed in the intercondyloid notch, its articular surface being directed outwards. The skin over it was tightly stretched, and the leg was semi-flexed, and lying on its onter side. He denied having received any blow on the knee, or that it had ever before been injured. Reduction was readily effected by forcibly flexing the leg and thigh, and then rapidly extending the limb. No synovitis of any consequence followed, and he left the hospital on November 7 th with the full use of his leg.

Remarks by Mr. NANkIVELL -Dislocations of the patella are by no means common accidents. These are the only cases I have met with in twenty years' hospital practice.
In luxation upwards the ligament must of necessity be ruptured. The treatment, therefore, should be the same as for fracture of the bone. Its efficacy is well shown in Case 2, although the patient twice dislocated the same patella, yet firm union of the ligament ultimately took place. Case 1 unfortunately did not present himself for treatment till two months after the occurrence of the accident. Union could not therefore be hoped for. Vertical or axial dislocation of the patella is usually caused by direct violence. The patient in Case 3 distinctly denied having received any blow on the knee. Accepting therefore his statement, and looking at the nature of the accident, which was a fall backwards, I think we are justified in assuming that in attempting to save himself he forcibly contracted the quadriceps muscle and thus caused the luxation. According to Malgaigne the outer edge of the bone is the part usually turned backwards. In the case under consideration it was the inner one which became fixed in the intercondyloid fossa. No difficulty was experienced in reduction, the bone being readily replaced by forcible flexion and extension of the leg and thigh.

\section{YEATMAN HOSPITAL, SHERBORNE.}

\section{CANCER OF THE UTERUS TREATED WITH NEGATIVE} RESULTS BY CHIAN TURPENTINE.

(Under the care of Mr. N. E. DAviEs.)

Mrs. H- was admitted early in November, 1880, for severe uterine hæmorrhage. On examination it was found that the cervix uteri was infiltrated with a mass of cancerous deposit as large as a turkey's egg. There was profuse fetid discharge with great pain. The patient had had one child when eighteen years old, and none after. There was no family history of cancer, her mother being still alive, and father recently died at over eighty years of age. The case was deemed a fair one for a trial of Chian turpentine, and a gross of the pills was procured from Messrs. Ferris and Co., of Bristol, who guaranteed them made according to Professor Clay's directions. These were taken one every four hours, with no other medicine whatever, with the exception of an occasional aperient. At the end of twenty-four days there had been not the slightest improvement whatever. A second supply of pills were then obtained with the view of giving the alleged remedy a thorough trial, but with the same result. The discharge of matter continued equally profuse during the whole time the patient took the drug; the cancerous mass lost none of its size, and the pain was not relieved. Feeling, then, it was useless to trust further to this remedy, the patient was put under a sedative treatment, both internally and locally, and und $t r$ this she derived at least freedom, or comparative freedom, from pain. She left the hospital after a stay of three months, preferring, as she expressed it, "to go home to die"-which she did in the August following.

Remarlis by Mr. DAvIES. - I am inclined to believe that a remedy, the beneficent action of which cannot be denonstrated by any physiological hypothesis whatever, runs some danger of beiug consigned to the limbo of vaunted remedies that have been found wanting; and the number of cases reported in a former issue of THE LANCET, carefully tried at the Middlesex Huspital, do not lend much encouragement to a further trial of this drug. A growth that is so swift in its development that it arrives at maturity and perishes long before the structures it is implanted in, must be attacked in its very earliest stage to offer any chance of success; and how this is to be done is at present, apparently, one of the hidden secrets of the future.

Royal Free Hospital. - On the 2nd inst. the fifty-fifth annual meeting of governors was held in the Board-room, at which the secretary read a report which was in many respects regarded as most satisfactory. The receipts from all sources during the past year amounted to $£ 11,486$, consisting of $£ 1932$ in donations, subscriptions $£ 963$, Jegacies $£ 7216$, with sundry receipts amounting to $£ 1375 ; £ 618 \mathrm{had}$ been received from the Hospital Sunday Fund, $£ 252$ from the Hospital Saturday Fund. Patients to the number of 1616 had been admitted during the year, the daily average being 122, as against 88 in the previous year; while 21,362 out-patients received adrice and medicine during the same period. During the small-pox epidemic in London only two cases occurred in the wards. 